\title{
Engaging diverse student audiences in contemporary blended learning environments in Australian higher business education: Implications for design and practice
}

\author{
Graeme Pye \\ Deakin University \\ graeme.pye@deakin.edu.au \\ Dale Holt \\ Deakin University \\ dale.holt@deakin.edu.au
}

Scott Salzman
Deakin University
scott.salzman@deakin.edu.au

\section{Emilia Bellucci}

Deakin University

emilia.bellucci@deakin.edu.au

\author{
Luisa Lombardi \\ Deakin University \\ luisa.lombardi@deakin.edu.au
}

\begin{abstract}
This research reports on a student audience engaging in an Australian university's undergraduate commerce program information systems core unit that is offered across three separate geographic campus locations and online. The research extends upon work undertaken on student engagement within the located domain of blended learning environments and juxtaposes the online perspective in an Australian higher education business context. Findings, inter alia, are presented across seven major student engagement dimensions as applied to the interplay between online and located/campus learning (i.e. Online Active Learning, Online Social Interaction, Online Collaboration, Online Teaching, Online Assessment, Online Academic Relevance and Online Contact with Staff). Implications for blended learning design, eLearning and practice in such complex online environments are examined.
\end{abstract}

Keywords: higher education; technology; student engagement

\section{Introduction}

Student engagement is an important predictor of student academic success, satisfaction and retention rates within undergraduate courses and university more broadly. This research represents the initial findings of a two year project investigating student engagement experiences of learning utilising a contemporary online blended Learning Management System (LMS) environment. The research investigates student engagement in a foundational disciplinary business subject offered in a large Faculty of Business and Law in a major Australian university using such an LMS. The University in question operates across three campuses in three separate cities in metropolitan, regional and rural settings in the Australian State of Victoria. It has a long and distinguished history in the provision of distance and online education. Australian and international universities continue to strategically seek competitive advantage by exploiting information and communication technologies (ICT) to service students, irrespective of their study location, through extending the options for flexible education, distance education, eLearning and online blended learning environments. The site of this research, Deakin University, has committed to the aspiration of pushing the digital frontier, with its own blended Cloud (online) and Located (physically in 
situ) learning multi-modal vision. Located learning settings encompass primarily the University's various distributed campuses, although its learning centres and designated workplace settings of relevance to its work-integrated learning programs can also be considered as part of an expanded view of where valued located learning occurs.

The research aims to inform, enhanced delivery and the quality of business education in Australian higher education by eliciting the student engagement factors and the dynamic interplay of student learning in the Cloud, and physically Located in situ on campus by:

- $\quad$ Developing, piloting and refining a student engagement survey instrument related to Cloud (online) and Located (in situ) Learning;

- $\quad$ Ascertaining the nature and extent of student engagement in such blended learning environments; and

- Developing a set of design principles and practices to enhance student engagement.

This paper presents findings from the administration of a student engagement survey to students enrolled in a large, first year core subject on business information systems offered in the Faculty's commerce program. The findings focus on the online student engagement factors of students, as opposed to staff teaching experiences in a blended learning environment. The unit is offered physically in situ across three located campuses and offcampus in the Cloud. The survey was based on significant international work reported in the higher education literature relating to the key dimensions of student engagement in the use of online learning systems in the context of their increasing adoption in campus-based settings. The research focuses on ubiquitous LMS environments and not on the more specialised educational technology field of 2-Dimensional and 3-Dimensional gaming and simulation spaces, including, for example, student engagement in 3-D platforms like Second Life (see Holt, Segrave \& Cybulski, 2011). Implications for design and practice enhancements in such mainstream LMS environments are considered along with future developments in the research.

\section{Background}

\subsection{New blended learning environments in higher education}

The positioning of this research is distinctive, yet indicative of the multi-dimensional blended learning environments employed in the Australian higher education sector, with a specific focus on the business education domain. In particular, Deakin University's Faculty of Business and Law offers most of its programs in multi-modal form both in the Cloud and Located at multiple campus locations. Program design, delivery and teaching practices have evolved to provide multi-modal study options and flexibility in students' choice of units and delivery modes of blended learning environments. ICT have been designed and implemented to further facilitate and enable these various study options. ICT along with its now mobile forms, driven by a flexibility imperative is leading to the convergence of all modes of learning around contemporary online blended learning environments.

Traditional synchronous and asynchronous modes of distance education has been a major global force over the last forty or more years, as manifested in the establishment of a large number of dedicated national Open Universities, using successive waves of ICT innovation and development (Daniel, 1996). The most recent manifestation of distance education in the form of eLearning can be found in the global reach of providers of Massive Open Online Courses (MOOCs) which are being originated by a broad range of higher education institutions. Some of their offerings are being used to enrich the on-campus learning experience. (For example, see the Special Edition of Distance Education on research and development of MOOCs in global higher education, 2014.)

Running in parallel with the expansion of global distance education offerings, has been the emergence of more flexible and blended forms of provision emerging out of the growing use 
of ICT in traditional campus, residential-based universities, in school programs and through major workforce training provision around the world (Bonk \& Graham, 2006; Latcham \& Jung, 2010; Kristin, 2013). These developments have revolved around the reconfiguration of the provisions of classroom (located) teaching and online learning. This reconfiguration involving both the nature and amount of both types of provision has a special focus on attempts to reinvent campus/site-based education in the wake of ICT developments sweeping over the entire educational and training sectors. Garrison and Vaughan (2008) and Shea (2007) highlight the need for blended approaches to be well integrated and mutually reinforcing in value to student learning. Distance education remains attractive to matureaged students, often in employment and/or with significant personal responsibilities, wishing to have an accessible and quality distance education experience. Likewise, blended approaches to learning has been grounded in the need to provide a better quality and more flexible learning experience for younger students who are predominantly studying in campus-based (located) environments. Both located and online learning are relatively discrete with learning provisions targeted to two reasonably well defined and different student cohorts. This study focuses on the major convergence of these two types of learning modes where traditional conceptions of on-campus, off-campus, classroom and online, have begun to dissolve in the face of the imperative for maximum flexibility in the ways students organise their studies in their increasingly hectic lives of work and play.

This notional convergence or blending of the located and online learning environment, is exemplified at Deakin University as CloudDeakin. This Learning Management System (LMS) seeks to deliver a single blended learning environment that is both engaging and relevant to each respective Located (in situ on-campus) and Cloud (online) student cohorts, as per Figure 1.

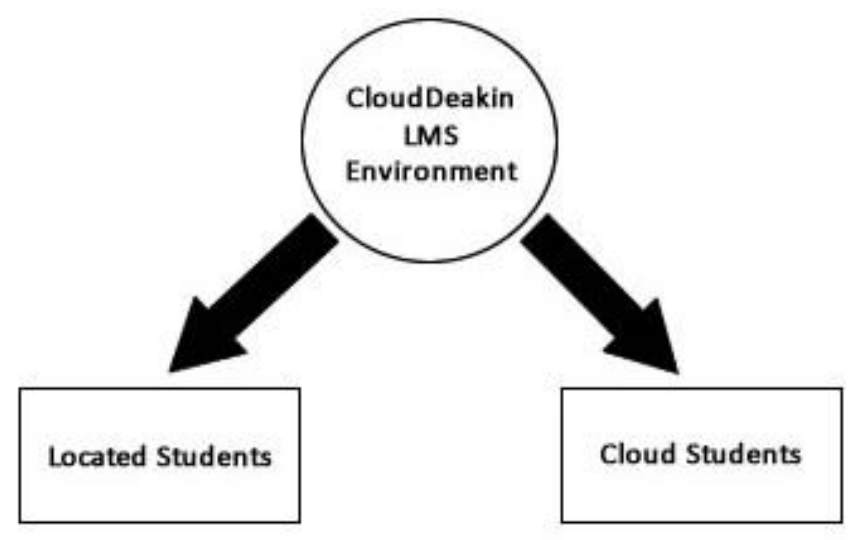

Figure 1. CloudDeakin LMS structure

\subsection{Investigating blended and online learning through the lens of student engagement}

Various lines of conceptual framing have been developed to promote students learning online. Some of these conceptual frameworks have been grounded in eLearning in distance education. Notably, for instance, the work of Salmon (2011) and her five-stage, scaffold model for enabling collaborative learning, and that of Garrison and Anderson (2003) and their three interrelated presences (Cognitive, Social and Teaching) for enabling robust online communities of inquiry. Bonk and Zhang (2008) developed a practical Read, Reflect, Display and Do (R2D2) model for online learning which is primarily directed at using different sensemaking modalities, and with broader applicability for designing both online and blended learning.

The current research aims to examine student perceptions of their experiences of evolving online and blended learning environments through the 'student engagement' frame of reference. The study of student engagement can be most directly related to the empirically 
well-grounded work of Garrison and Anderson (2003) who draw heavily on various dimensions of interactivity promoted by educational technologies in developing their conceptual framework, namely: teacher-student interaction; student-student interaction; student-content interaction; teacher-teacher interaction; and content-content interaction. They also featured prominently the importance of social and teaching presence in building effective online learning communities.

The research contributes to the large body of work on promoting student learning in online and blended learning settings in two important respects. First, it adds to the research undertaken on student as opposed to staff experiences of blended learning and teaching (see Graham \& Robison, 2007; Kaleta, Skibba \& Joosten, 2007). Second, the aim here is to seek student perceptions so as to investigate how students are practising engagement at university, based on a strong line of higher education research in this domain and to extend these investigations into the particular field of students engaging with online and blended environments.

Student engagement focuses on the time and effort students put into purposively designed educational activities directed at achieving desired learning outcomes. Student engagement is seen as a proxy for quality student experiences and outcomes. It has been well conceptualised, theorised, researched and actioned in the US (Kuh, 2003; Kuh, Kinzie, Schuh, Whitt \& Associates, 2005). It has been adapted to Australian conditions through the work of Scott (2006) in analysing Course Experience Questionnaire (CEQ) open-ended comments, the Australasian Survey of Student Engagement (AUSSE, see ACER website) and the more recent University Experience Survey (UES). A major leader in the development of these surveys has been Hamish Coates, formerly at the Australian Council of Educational Research (ACER), then the L H Martin Institute and followed by being Director of the Centre for the Study of Higher Education (CSHE) at the University of Melbourne (see Krause \& Coates, 2008; Coates, 2010). Coates (2006) investigated how learning technologies, as particularly prominent through the large-scale implementation of Learning Management Systems (LMSs) throughout higher education, were impacting campus-based student engagement.

Taking account of the more general set of dimensions constituting student engagement, Coates (2006) developed a set of student engagement constructs for online learning environments (as related to online learning engagement in campus-based settings). This set of dimensions are directed at finding out what students self-report that they actually do online, as opposed to what teachers might think they should be doing. Coates' approach elicits student views on what and how much they have done of relevance to their academic pursuits. These constructs of online student learning inform the development of a student engagement survey for Cloud (online) and Located (campus) Learning in this research relating to a business education context.

The research adapts the work of Coates (2006) to blended learning in contemporary educational technology contexts, and represents a unique niche in the myriad of investigations on student learning online. The only line of research identified which has investigated the intersection of blended learning and student engagement is reported by George-Walker, Hafeez-Baig, Gururajan and Danaher (2010). Two of their cases related to postgraduate business education in the field of information systems and information technology. While the prior work of George-Walker et al. (2010) was evaluated, their work was not directly informed by the student engagement literature or the survey method of data collection in the student engagement domain.

\subsection{Key characteristics of blended learning environments}

For the purposes of this research, 24 elements constituting developments in blended learning have been identified by the research team. These are the factors that can be chosen and varied in the design and practical operation of blended learning environments. These factors will be discussed further under the findings implications. 


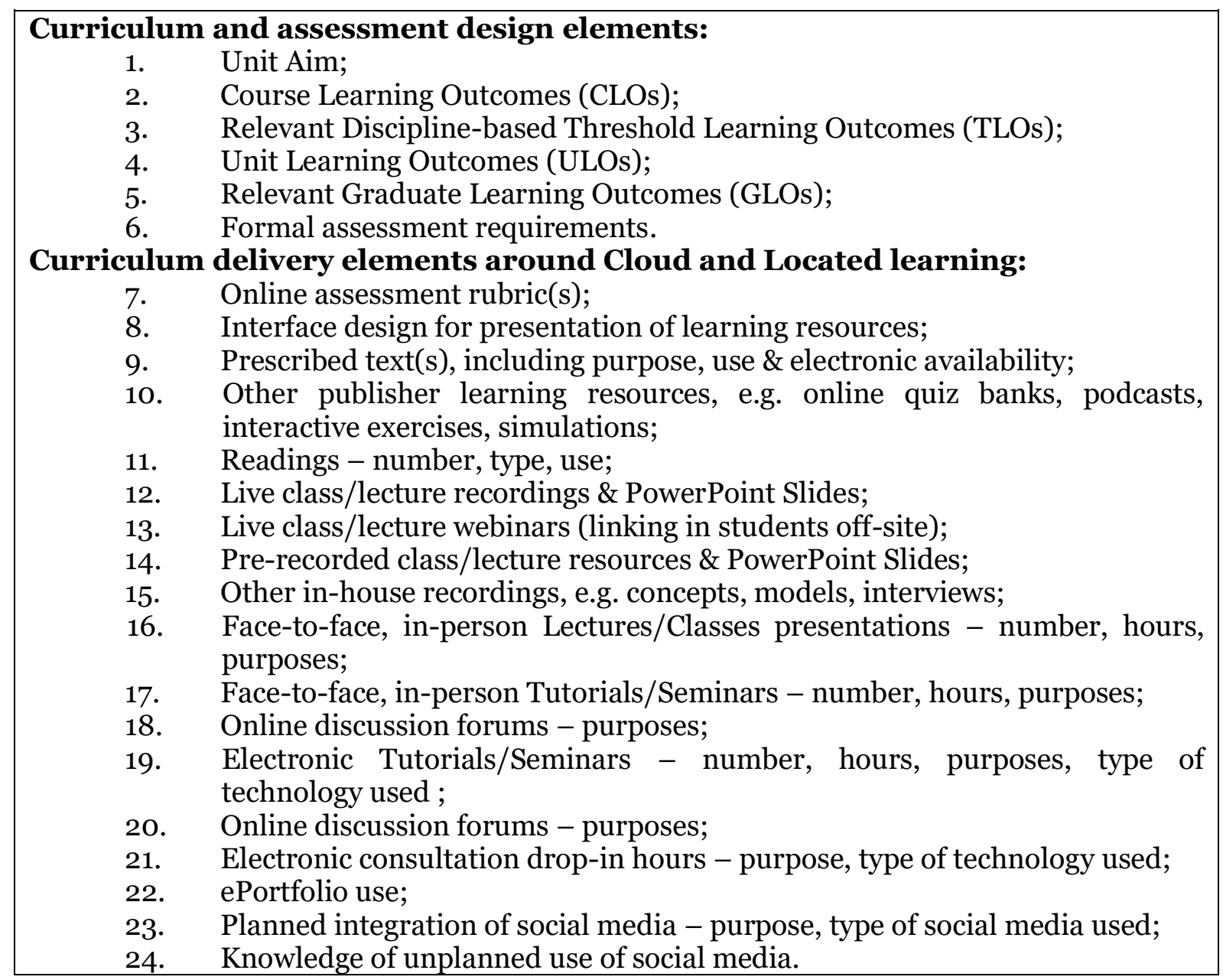

Table 1: Key characteristics of blended learning environments

\section{Research methodology}

\subsection{Scope}

The research is being conducted over two years (2014-2015) involving surveying students undertaking undergraduate business education studies in Business Information Systems, which is a first trimester, first year, core unit in both the commerce and information systems undergraduate programs.

Business Information Systems is a very large commencement study unit and plays an important role in helping students in transitioning into studies in higher education in the business realm. The unit chosen is seen to be representative of major developments in Cloud and Located learning in business education, in the Faculty.

\subsection{Theoretical frame of reference}

Citing Coates (2006, p.69), student surveys are structured conversations between learners and universities. This research uses a survey design to ascertain student views on how, and how much, they are engaging with the Cloud and Located learning environments. The online survey method used is self-selecting and gives the most number of students the opportunity to share their views on what they have personally experienced. Drawing on an already developed, trialled and validated student engagement survey related to online learning in campus contexts by Coates (2006), the survey developed for this research is relevant to the online student experiences to be elicited, and efficient to administer with large student cohorts. The six key dimensions of the survey, cover: 
1. Online active learning: key ways in which students use online systems to construct and enhance learning;

2. Online social interaction: use of online learning systems to support general forms of social interaction;

3. Online collaboration: students' use of online systems to work collaboratively with peers;

4. Online teaching: whether teachers use online learning systems to promote effective learning;

5. Online academic relevance: use of online systems to enhance the relevance and context of study;

6. Online contact with staff: extent and ease of use of online systems by students in contacting staff.

\subsection{Online student engagement survey design}

The student engagement survey used the preceding six key dimensions identified by Coates (2006) and associated activities indicating quality and quantity of time and effort related to each. A seventh student engagement dimension was added relating to various activities associated with Online Assessment. The assessment management features of Learning Management Systems are seen as key benefits in supporting teaching and student learning online. Assessment review and improvement is seen a major means of enhancing the student learning experience in higher education (Boud, 2010; Boud \& Molloy, 2013; Nicol, 2010). Focus on assessment has been a major driver in reviewing and renewing curriculum design and delivery in Australian higher education, as advanced by senior university educational leadership (see Lawson, 2015; Oliver, 2013). It was seen as highly pertinent to student engagement with contemporary curricula and enabling learning environments to foreground assessment as a key dimension of student engagement in this research. In addition to the seven dimensions of student engagement, several other pertinent factors were surveyed as summarised in Table 2.

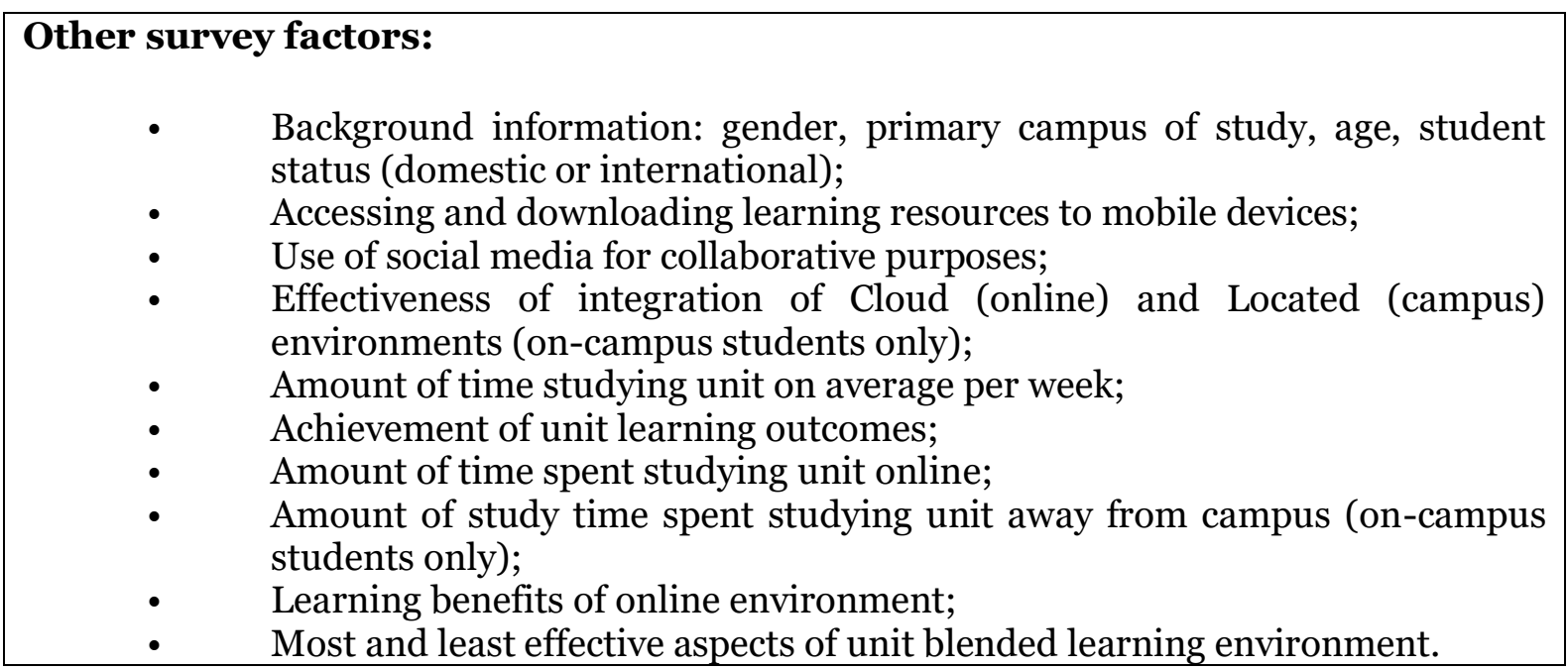

Table 2: Other survey factors

\subsection{Data collection and response rate}

This paper reports on summary data collected from students studying a major first year unit, Business Information Systems (BIS), which is a core unit in the undergraduate Bachelor of Commerce degree at Deakin University. Data collection was undertaken anonymously using self-selection sampling via an online survey of student participants utilising an online survey 
tool (called "Opinio") administered through the Strategic Intelligence and Planning Unit at Deakin University during Weeks 8 to 11 of Trimester 1, 2014. The research project and survey instrument received ethics approval from the Faculty's Ethics Committee. The total number of enrolled student invitee emails was 1345. The response rate is shown in Table 3.

\begin{tabular}{|l|r|r|r|r|}
\hline & Population & Sample & $\begin{array}{r}\text { Response Rates } \\
\text { (1345) }\end{array}$ & $\begin{array}{c}\text { Response Rates } \\
\text { (138) }\end{array}$ \\
\hline $\begin{array}{l}\text { Invitees } \\
\text { (Totals): }\end{array}$ & 1345 & 138 & $10.26 \%$ & $75.36 \%$ \\
\hline $\begin{array}{l}\text { Invitees: } \\
\text { (Survey } \\
\text { Completions): }\end{array}$ & 1345 & 104 & $7.73 \%$ & $24.63 \%$ \\
\hline $\begin{array}{l}\text { Invitees } \\
\text { (Survey } \\
\text { Incompletes): }\end{array}$ & 1345 & 34 & $2.53 \%$ & $99.99 \%$ \\
\hline Total: & & 138 & $10.26 \%$ & \\
\hline
\end{tabular}

Table 3: Survey response rates for completions and incompletes

Comparisons between sample and population demographic and background factors is presented in Table 4.

\begin{tabular}{|c|c|c|}
\hline & \multicolumn{2}{|c|}{ Students } \\
\hline & Sample & Population \\
\hline No. of respondents & 104 & 1345 \\
\hline Response rate (completions) & $7.73 \%$ & - \\
\hline \multicolumn{3}{|l|}{ Gender } \\
\hline Female & $44(42 \%)$ & $503(38 \%)$ \\
\hline Male & $60(58 \%)$ & $842(62 \%)$ \\
\hline \multicolumn{3}{|l|}{ Mode of enrolment } \\
\hline Located/on-campus & $83(80 \%)$ & $1194(89 \%)$ \\
\hline Cloud/online/off- campus & $21(20 \%)$ & $151(11 \%)$ \\
\hline \multicolumn{3}{|l|}{ Campus } \\
\hline Melbourne Burwood & $60(58 \%)$ & $898(67 \%)$ \\
\hline Geelong Waterfront & $15(14 \%)$ & $254(19 \%)$ \\
\hline Warrnambool & $8(8 \%)$ & $42(3 \%)$ \\
\hline Cloud/online/off- campus & $21(20 \%)$ & $151(11 \%)$ \\
\hline \multicolumn{3}{|l|}{ Domestic/International } \\
\hline Domestic & $95(91 \%)$ & $1218(91 \%)$ \\
\hline International & $9(9 \%)$ & $127(9 \%)$ \\
\hline \multicolumn{3}{|l|}{ Age } \\
\hline 18-21 & $71(68 \%)$ & $1001(74 \%)$ \\
\hline 22-25 & $8(8 \%)$ & $223(17 \%)$ \\
\hline 26-30 & $6(6 \%)$ & $54(4 \%)$ \\
\hline 31-36 & $12(11 \%)$ & $41(3 \%)$ \\
\hline $37-42$ & $1(1 \%)$ & $13(1 \%)$ \\
\hline Above 42 & $6(6 \%)$ & $13(1 \%)$ \\
\hline
\end{tabular}

Table 4: Sample and population comparisons 
The survey system saves responses after each page is complete, so some partially completed responses exist. In the survey analysis, the maximum applicable number of useful responses is used.

In the sample, $58 \%$ were female and $42 \%$ were male. These proportions are not significantly different. The sample statistics indicate that females make up somewhere between $48 \%$ and $67 \%$ of the student population, and males make up somewhere between $33 \%$ and $52 \%$ of the population. However, the University Student Information System (SIS) database unit population records indicate that there are 504 females and 802 males enrolled, representing $37 \%$ females and $63 \%$ males. Gender is, therefore, disproportionately represented in the sample. Whilst data on the gender of participants is not the focus of this research, the results do conform to other surveys conducted online. Just as it is well known that pleasure seekers are less likely to respond to an online survey (Sax, Gilmartin \& Bryant, 2003), research also indicates that unmarried people, females and older students are more likely to respond to online surveys (Dey, 1997; Johnson, O’Rourke, Burris \& Owens, 2002; Cull, O'Connor, Sharp \& Tang, 2005). More specifically, females are more likely to respond in online surveys (Rogelberg \& Luong, 1998). Moreover, whilst we recognise the likelihood of a degree of selfselection bias, we also recognise the potential for committed self-selecting participants.

\subsection{Data analysis}

All data was managed using Microsoft XL 2013 and analysed using XL Statistics Version: 09.09.14. It is noted that the inherent bias often present in online surveys implies that it is possible that some groups might be disproportionately represented and therefore, generally numerical summaries are presented and discussed. However, where applicable, to assess for differences between two means, the t-test was used, and where hypotheses tests applied, critical alpha was set at 0.05 .

\section{Findings}

A summary of findings is outlined under key survey headings.

\subsection{Study time, allocation and achievement of unit learning outcomes}

Considering the BIS unit is a commencing unit for students' tertiary studies, their perceptions of amount of time spent studying the unit, the amount of time spent studying online and whether they believed they had achieved the unit learning outcomes becomes critically important. Twenty-two percent of respondents spend no more than 4 hours studying each week, and possibly as many as 36\% of students spend at least 6 hours studying each week. Forty-eight percent of responding students spend more than $50 \%$ of their study time studying away from campus (where relevant) but online. Seventy-five percent of responding students indicated that they dedicate at least $10 \%$ of their study time to activities online.

Eighty-three percent of responding students believe that they achieved the unit learning outcomes to at least some extent. The normal expectation is that students would be expected to spend 8-10 hours a week studying the unit. Clearly, a significant number are below this expectation as shown in Figure 2. 


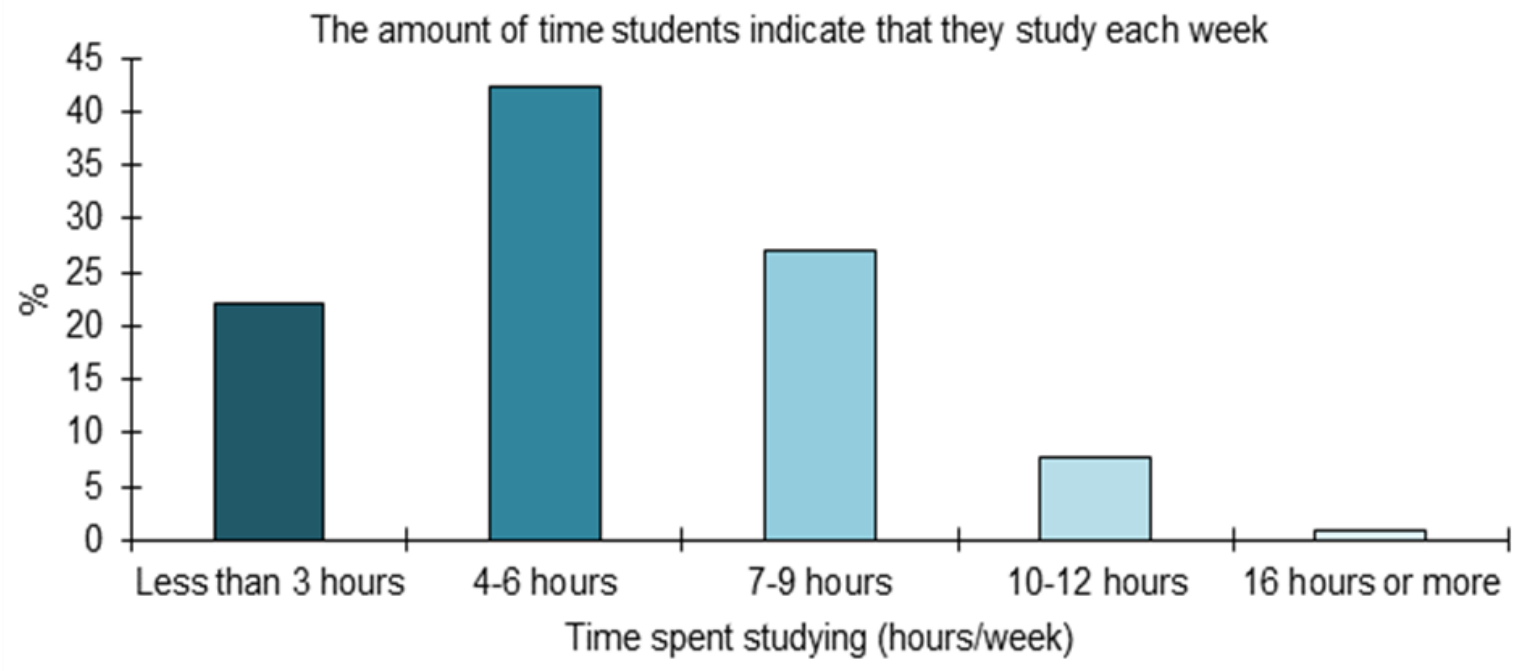

Figure 2. The amount of time students indicate they spent studying each week

It would be expected that most students would master the unit learning outcomes fully or to a large extent. Again, students' perceptions fell below that benchmark as shown in Figure 3.

How students percieve that they achieve the intended learning outcomes as a funciton of the amount of time they indicate that they

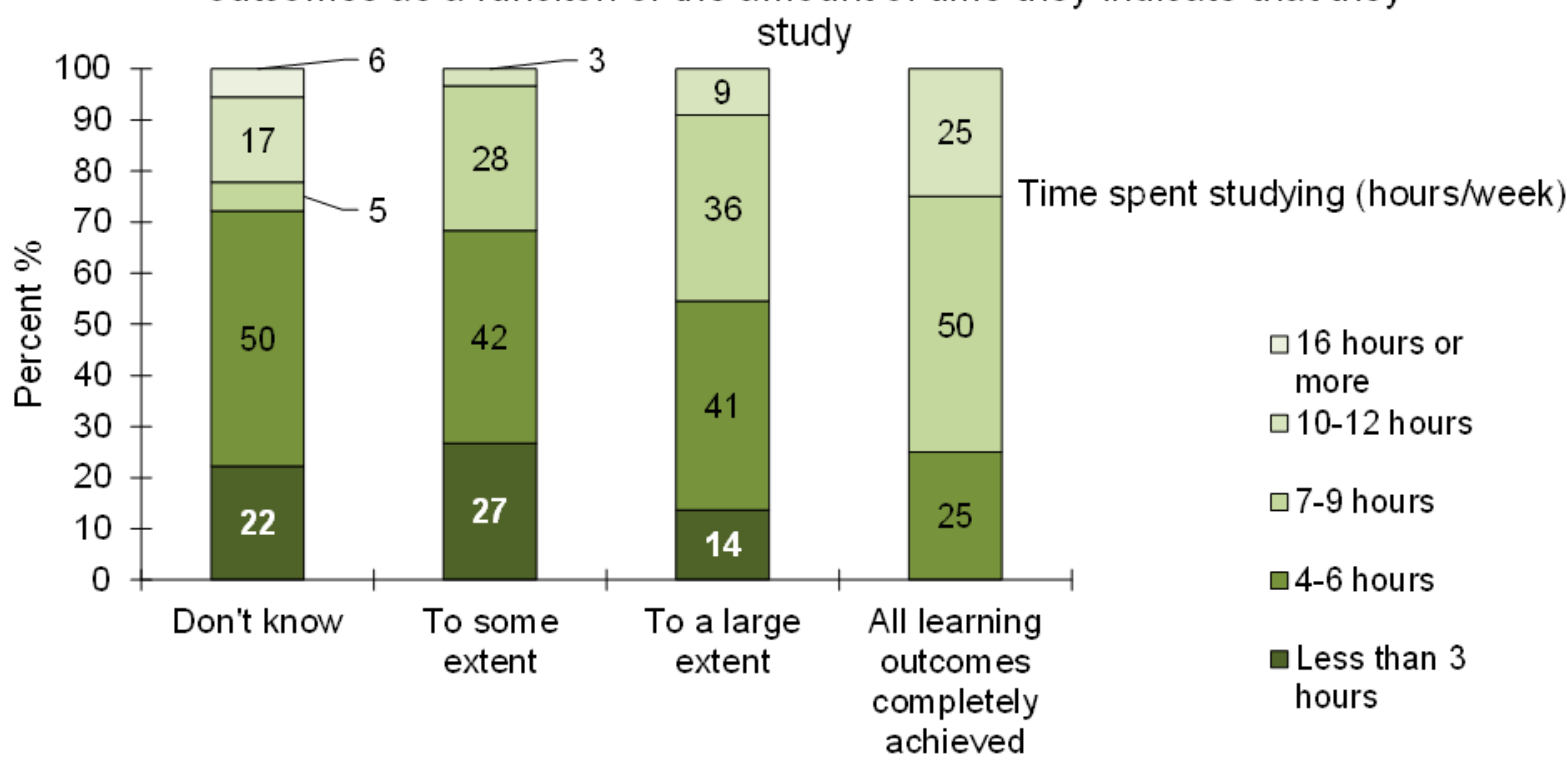

Given the amount of time you spent studying, do you think you achieved the intended learning outcomes?

Figure 3: Perceived extent of learning outcomes met as a function of the amount of time students indicate that they spent studying

Implications for designing and operating blended learning environments to reinforce and challenge students to spend more, better and the appropriate amount of time on the unit to achieve its objectives is addressed at the end of the paper.

In relation to cross-tabulating study time with the student engagement constructs significant differences were evident in the following: 
- Those who indicate that they are studying 10 to 12 hours per week, also indicate that they will score less on questions themed in the Social Interaction construct (3.09 compared to $3.74,3.88$ and 4.05).

- Those who indicate that they are studying 10 to 12 hours, are more likely to score higher on the Teaching construct items than those who indicate that they are only study for less than 3 hours per week (5.02 compared to 4.62).

- Those who indicate that they are studying 10 to 12 hours per week, are more likely to score higher on the Staff Contact items than those who indicate that they are only study for less than 3 hours per week (4.67 compared to 3.74 ).

- In amount of time spent studying between on- and off-campus students. That is, when considering both on- and off-campus cohorts, off-campus students indicate that they are studying more. For example, $55 \%$ of the off-campus students in the sample indicate that that they are studying more than 6 hours, whereas only $30 \%$ of the on-campus students indicated that they were making this kind of effort.

\subsection{Perceived integration of cloud and located learning environments}

The proportion of the student population who believe that (1) 'Cloud and Located learning enhanced each other' and (2) 'Cloud and Located learning were relevant to each other' was 74.7\%. Similarly, the proportion of the student population who believe that (3) 'The connection between Located and Cloud Learning was not always clear' and (4) 'There was little or no connection between Located and Cloud Learning' was 25.3\%. Indicating classroom dimensions of complex blended learning environments is a complex and ongoing challenge.

\subsection{Perceived learning benefits}

Fifty-three percent of the student population believed that the online system maximised their learning from on-campus classes (Conversely, it could also be true that $20 \%$ of the student population DID NOT believe that the online system maximised their learning from oncampus classes); $84.27 \%$ of the student population believed that the online system allowed them to organise their study time more effectively (Conversely, $7 \%$ of the student population DID NOT believe that CloudDeakin allowed them to organise their study time more effectively); and $89.25 \%$ of the student population believed that the online environment allowed them to learn the subject materials more conveniently (Conversely, $5 \%$ of the student population DID NOT believe that the online environment allowed them to learn the subject materials more conveniently).

The youngest age group ( $18-21$ year olds) are more likely to think that the online system aided in maximising their learning from on-campus classes. Suggesting, the older a student gets, the less likely they are to think that the online system maximises their on-campus (in class) learning experience.

\subsection{Online active learning}

Eighty-eight percent of students believe that online content materials could be used to improve learning; $76 \%$ of students indicate that online materials make classroom (Located) learning more meaningful; 91\% indicate they would identify expected academic standards using the online environment; $59 \%$ indicate that online materials challenged them to learn; $29 \%$ reveal that they would never use a mobile device to access the online environment; and $53 \%$ state they would never use a mobile device to access AND download resources from the online site.

Compared to any other age group, younger people are significantly less likely to be challenged with online learning materials. Further, younger students (18-21 year olds) are less likely to think that staff used the online system to clarify what was required to do well. 


\subsection{Online social interaction}

Seventy-eight percent of the respondents indicate that teaching staff participated in online discussions; $57 \%$ indicate it was easy to explain their ideas in online discussions; $49 \%$ indicate that they had helpful online discussions with other students; $28 \%$ reveal they met new people when using the online environment. These findings suggest a moderating of value attributed to traditional asynchronous discussion boards on LMS-type environments. The majority of students surveyed indicated Facebook was their preferred technology for social interactivity and collaborative purposes. Reasons why Facebook was preferred related to ready access to notification alerts and privacy of conversations.

A cross-tabulation by mode of enrolment showed a significant difference as evident. That is, off-campus students are likely to score higher on questions themed in the Social Interaction construct ( 4.3 for off-campus compared to 3.7 for on-campus students).

\subsection{Online collaboration}

Thirty-three percent of the on-campus student population used the online system with other students around the campus. Conversely, $21 \%$ of the on-campus population DID NOT use the online system with other students around the campus. Twenty percent of the on-campus student population used the online system to work with other students outside the class. Conversely, 37\% of the on-campus population DID NOT use the online system to work with other students outside the class. Thirty-three percent of the population used the online system to do academic work with other students. Conversely, $33 \%$ of the student population DID NOT use the online system to do academic work with other students. Thirty-nine percent of the student population used the online system to communicate with other students. Conversely, it could also be true that as many as $32 \%$ of the student population DID NOT use the online system to communicate with other students.

A cross-tabulation by Gender showed a significant difference was evident as shown in Figure 4 .

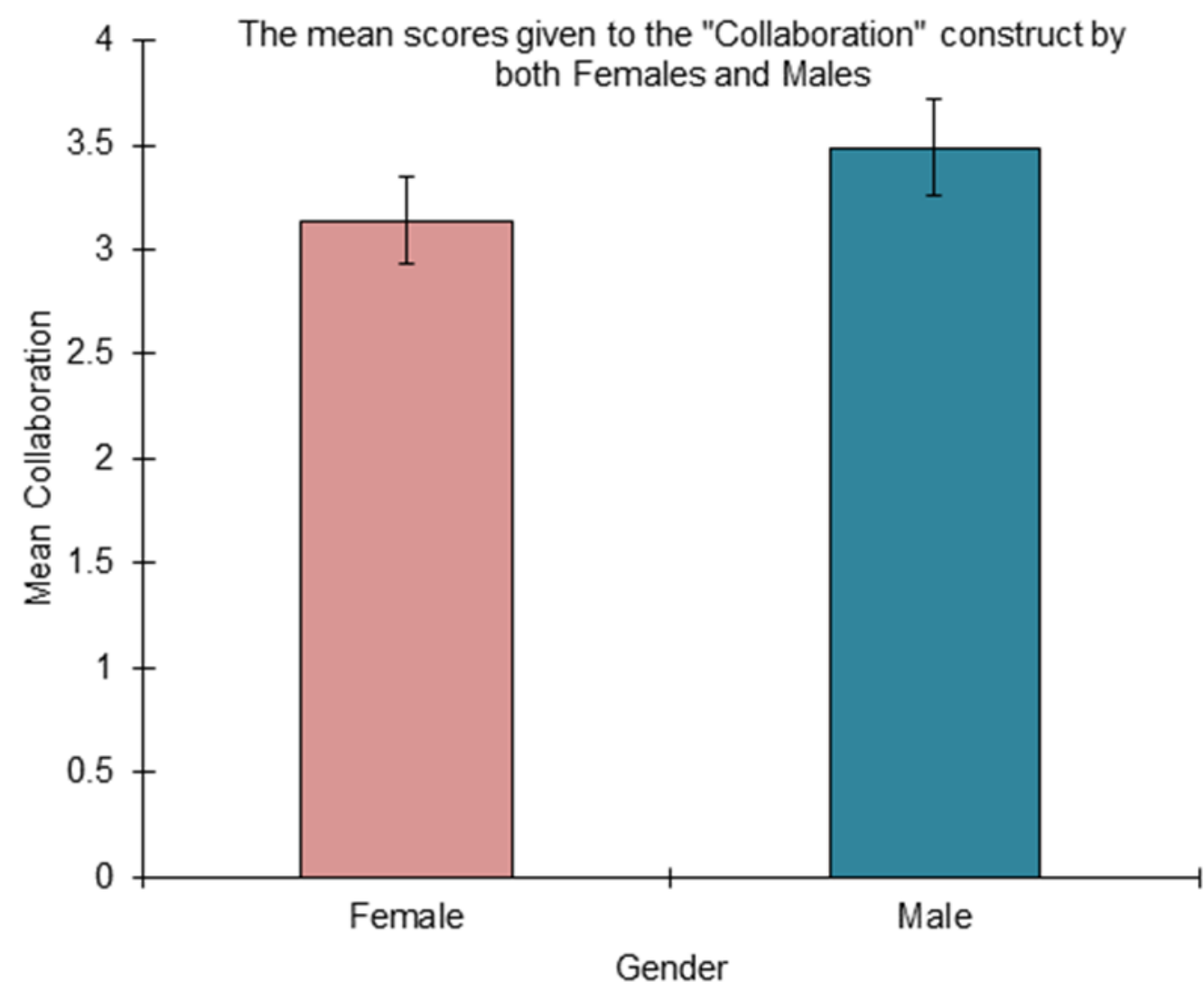

Figure 4: Gender difference regarding the construct "Collaboration" 
Figure 4 illustrates that males are likely to, on average, score higher on questions themed in the Collaboration construct (3.49 for males compared to 3.14 for females). A cross-tabulation by mode of enrolment also showed a significant difference was evident. That is, off-campus students are likely to score higher on questions themed in the Collaboration construct (2.7 for off-campus compared to for on-campus students).

Compared to any other age group, younger people (18-21 year olds) studying on-campus are significantly more likely to use the online system with other students around the campus.

\subsection{Online teaching}

Eighty-two percent of the student population believes that staff used the online environment to clarify what was required assessment-wise to do well; $82 \%$ of respondents believe that staff used the online environment in ways that improved overall teaching; $92 \%$ of respondents believe that academic staff made an effort to communicate with students online; $82 \%$ of responding students believe that academic staff used the online environment to provide students with extra assistance; $94 \%$ believe that teaching staff used the online site to tailor activities for students; and $69 \%$ believe that teaching staff used the online environment to discuss interesting issues. On the latter result, younger students (for example, those under the age of 30 years) are less likely to think that staff used the online system to discuss interesting issues.

In cross-tabulating with mode of enrolment a significant difference was evident. That is, offcampus students who responded are likely to score higher on questions themed in the Teaching construct (5.05 for off-campus compared to 4.71 for on-campus students). Offcampus students indicated that they received better clarity regarding what was required, compared to any other cohort in the unit.

The results overall indicate that teaching staff used the online environment solidly to advance their teaching intentions, and that students in turn saw it as a major component of their blended learning experience.

\subsection{Online assessment}

Eighty-five percent of the student population believes that assignments are easy to locate using the online environment; $90 \%$ of them believe tests are easy to locate online; $95 \%$ of responding students believes that assignments are easy to submit online, while five percent of responding students believe that assignments are not easy to submit online; $81 \%$ indicate that online assignment submission gives them more time to complete their work; $54 \%$ of responding students believe that online assignment feedback improved their understanding of the topic. (Conversely $21 \%$ of respondents indicate that online assignment feedback DID NOT IMPROVE their understanding of the topic.) $60 \%$ of responding students believe that online assignment feedback helped them prepare for subsequent assessable work. (Twentyfour percent of responding students believe that online assignment feedback DID NOT help them prepare for subsequent assessable work.) Evidence suggests online assessment facilitates a more convenient and effective means of engaging with unit requirements. A technical glitch in the operation of the system did compromise the value students perceived relating to assignment feedback through online rubric use. This is instructive to the extent that technical failures in systems of great importance to student learning can adversely affect student engagement factors.

\subsection{Online academic relevance}

Sixty-four percent of responding students believe that using the online system made study seem more relevant (Conversely, $17 \%$ of responding students DO NOT believe that using the online system makes study seem more relevant.); $75 \%$ of students believe that using the online system makes them feel like part of the university (Conversely, $18 \%$ of students DO NOT believe that using CloudDeakin makes them feel like part of the university.); and $64 \%$ of them believe that using online materials within the online environment helped them put their 
study in a real-world context (Conversely, $19 \%$ of students DO NOT believe that using the online environment helps them put their study in a real-world context).

A cross-tabulation by Gender showed that a significant difference was evident as depicted in Figure 5.

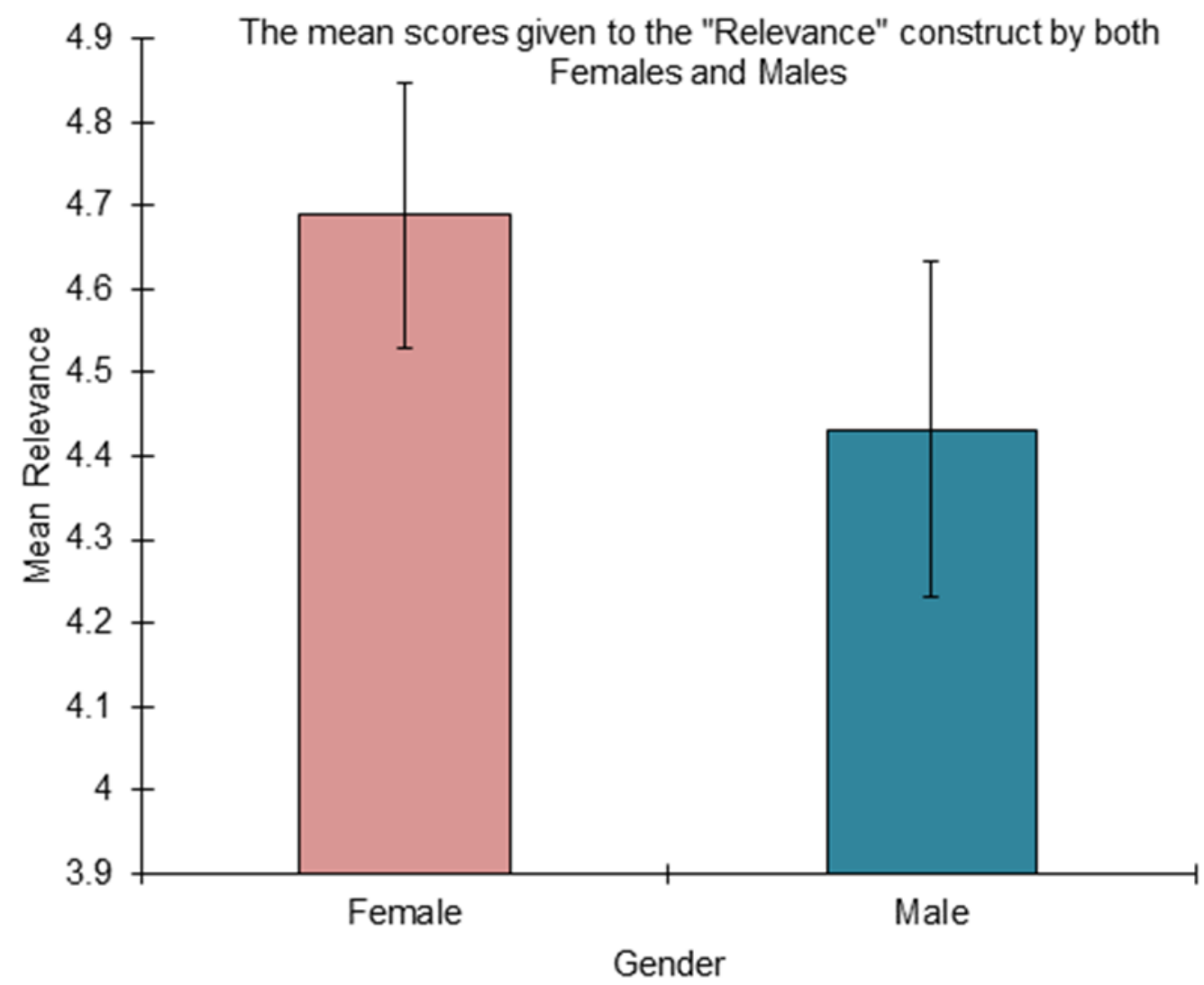

Figure 5: Gender difference regarding the construct "Academic online relevance"

Females are more likely to, on average, score higher on questions themed in the Relevance construct (4.69 for females compared to 4.43 for males). Compared to the 22 to 25 year olds, the 31- 36 year olds $(n=12)$ are less likely to think that the online environment made study more relevant.

\subsection{Online contact with staff}

Fifty-nine percent of responding students at least agree that they used the online system to contact staff. (Conversely, 19\% of students do not agree that they used the online system to contact academic staff.) Sixty-seven percent of responding students found it easy to communicate with staff online. (Conversely, $11 \%$ of responding students DID NOT find it easy to communicate with staff online.) Forty-six percent of participating students had individual contact with academic staff using the online system. (Conversely, 26\% of them DID NOT have individual contact with academic staff using the online system.)

Not surprisingly, off-campus students are more likely to use the online system to contact staff, than the other campus-based cohorts. Compared to the other three campus-based student cohorts, off-campus students found it easier to communicate with staff online, perhaps given their greater level of maturity. 


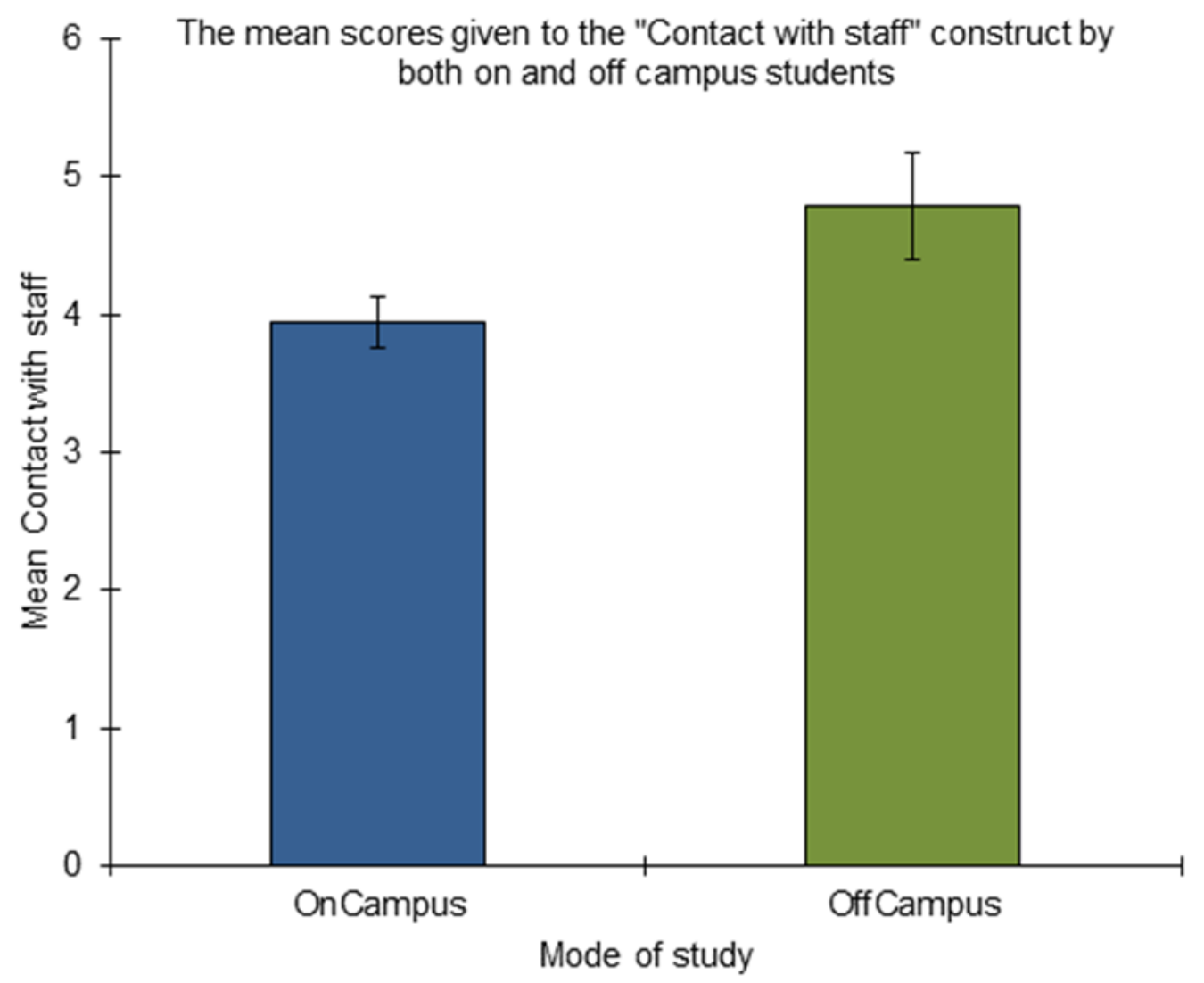

Figure 6: Mode of study difference regarding the construct "Contact with staff"

Cross-tabulating with mode of enrolment revealed that a highly significant difference was evident (Figure 6). Off-campus students are likely to score significantly higher on questions themed in the Contact with Staff construct (4.79 for off-campus compared to 3.94 for oncampus students).

\subsection{Most and least effective aspects of the CloudDeakin environment}

From an analysis of open-ended comments it was found:

- $\quad$ The structure of the online environment was predominately well presented for easy navigation and as the unit's only repository for materials. The only negatives were related to better notification of updated material and the use of rules/widgets to distinguish between read and unread material.

- The use of the system to submit assignments online was preferred to paper-based submission since it was easy and there was no printing involved.

- $\quad$ Students found the online system useful for flexible access to unit material 24/7. This enabled students to structure their learning around busy schedules, classroom clashes and part-time/full-time work.

- $\quad$ Access to online lectures was mentioned mainly as a positive, since it allowed students to catch up on missed classes, although not all students appreciated the system recordings, noting bad lecture recording quality and a negative perspective of the online offering due to comparisons made with other online course MOOC providers.

- The effectiveness of tutorials were mixed based on the location of students (located/campus, cloud/online-based). Located/on-campus students found tutorials quite effective, particularly in helping students to summarise their weekly classes and hence keep on top of the material. The lack of synchronous 
communication recordings of tutorials was a common complaint among cloud/online-based students, who noted that in previous classes cloud/onlinebased students have found these recordings very useful.

- The majority of students found the Discussion board on the LMS as very useful in preparing for assignments and would often use this area to uncover 'hidden tips'. A couple of students felt there was a delayed response to questions via the discussion boards and even after using the alert email system. One student found that not all the discussions he was alerted to were of interest, and hence was annoyed by the excessive number of email alerts. One student suggested questions should be moderated and deleted if they are more relevant to another thread to eliminate duplicated responses.

\section{Implications for blended learning design and practice}

\subsection{Framing the design and practice of blended learning around learning outcomes and assurance of learning}

Irrespective of the mode of delivery, the learning outcomes must be clearly established, and formal assessment directed at motivating students towards this achievement (Biggs \& Tang, 2011). Student engagement does in part relate to productive study time on tasks engendering quality learning and tasks must be aligned with the relevant learning outcomes. Students self-reported notional average weekly study time may under-represent the actual time spent on all aspects of their study. It is possible students were only considering contact time within the lecture, tutorial, consultation or online in CloudDeakin rather than the entire time spent studying, researching and reading. It might also be surmised that many students remain fundamentally results-driven focusing primarily on the next set of assessment activities to be undertaken and completed. Hence, they may not be immediately concerned with or paid little attention to, the achievement of the unit learning outcomes.

Therefore, blended learning educators need to highlight learning expectations in the first lecture relating to the hours students should dedicate to unit study per week, to reasonably achieve the unit learning outcomes. In this study, it seems a significant number of students were not on average spending the expected hours to achieve the desired learning. This is not an uncommon finding in student study patterns in Australian higher education. However, it is notable that the Cloud (online/off-campus) student cohort perceived that they tended to work harder in the unit compared to their Located (on-campus) student cohort counterparts.

It is clear that a significant number of students spend a substantial amount of their study time studying online, irrespective of their mode of enrolment. The incentive not to physically attend Located classes for those students enrolled in this mode is strong given the provision of all resources (including recorded lectures) online. The results, however, did not necessarily delineate separately between Located and Cloud learners. Convenient and ready access to all available learning resources to all students irrespective of mode of enrolment creates an ongoing dilemma in the design and operation of such learning environments. For the predominately younger school-leaver Located cohort, this form of remote engagement can be deleterious to the development of their communication, collaborative and networking skills. Furthermore, external course accreditation requirements in business education can demand that evidence of learning thresholds is provided to assure the development and assessment of specific professional capabilities amongst identifiable student cohorts. The removal of certain incentives for withdrawing into individualistic online study like removing the provision of recorded live lectures to the Located cohort can run up against faculty and institutional commitments to providing maximum options for flexible study. 


\subsection{Maximising the value proposition in designing blended learning environments}

From this analysis and discussion it is clear that it is a complicated challenge to maximise the teaching/learning value proposition in designing blended learning environments involving multi-campuses, multiple student cohorts and different types of student cohorts. The number and diversity of student needs and circumstances means that design and practice trade-offs are required. Irrespective of the amount and range of learning resources provided online, the investigation has revealed that thoughtful online systems' interface design including social media is essential in allowing students to easily locate and use the resources in achieving the desired learning. Learning resources and assessment tasks must be well organised around the determined curriculum structure and available in formats which make them easy to study online or download and use offline on various types of desktop and mobile computer devices. The structural and discretionary variation in unit sites can lead to quite different student interpretations of the ease of usability of each unit site with which they engage. Online learning system interfaces can be less web intuitive and Facebook-like than the information systems that the students may be more comfortable and familiar with in their own lives. Adopting a small set number of different templates that streamline the interface between units would develop familiarity and limit usability issues around locating relevant/specific learning resources and information, based on this investigation. The consistent and easy-touse interfaces of the major global Massive Open Online Course (MOOC) platforms have much to commend in this respect compared to the more limited interface design options of proprietary learning management systems (LMSs).

The investigation revealed the more limited downloading and use of learning resources on mobile devices than may have been expected, and this finding should be set in the context of a course being studied on ICT-enabled business information systems. A tentative conclusion reached, in this context, was that students perhaps use mobile devices to keep track of dates and discussions, rather than downloading resources for offline learning.

In relation to online communication and moderation practices, the study highlighted the need for a more active approach to the moderation of online discussions. In the case of this course's online learning system, the discussion postings were not easily 'search-able' and the message/posting settings can be seen as restrictive and counter-intuitive, requiring time for students to develop a familiarity with the online discussion features. Most students appear to use the online discussion forums as they would Facebook and post a message expecting a direct response from the lecturer, rather than reviewing the other postings first. There seems to be a challenge in generating student collaboration and collegiality online within traditional asynchronous discussion boards. Initially it takes time for the students to see the benefit of using discussion boards given that to them they must seem like an old technology solution to communication demands.

There now appears to be a trend in online distance education to move more from asynchronous online discussion forums to synchronous forms of discussion like eTutorials and eSeminars. After the completion of this study in this course, a 'pilot' trial consisting of using three synchronous communication sessions with Cloud students was only seen to have been somewhat successful. These gave the remote students and opportunity to speak directly with the Unit Chair in three, one hour long sessions. The use of such synchronous communication sessions requires far greater development and investigation.

While the provision of such direct opportunities for teaching staff-student interactions might engender stronger student engagement they might also carry the cost of reduced perceived student study flexibility to the detriment of their motivation to continue studying. In this study, there was some evidence that older students are perhaps more set in their learning styles and expectations and are less adaptable or accepting of new learning environments than younger students. This finding should not be discounted, although, on balance, adaptability and change should continue to be encouraged generally throughout the cohorts, 
particularly off-campus and mature-age students, in order to equip all students with the skills required for contemporary collaborative workplace practices.

In addition to institutionally supported LMS and other synchronous communication tools, evidence from previous studies suggests the increasing use of social media applications in supporting peer exchanges and cooperative endeavors (Evans 2014; Kelm 2011; Graham 2014). Evans (2014) found a strong causal relationship between Twitter use and student engagement in university activities and class based discussions, and similarly Graham (2014) found business students regarded the social dimension to learning and discussion among their team members made projects more enjoyable. The reasons why Facebook was preferred over other platforms, particularly compared to our LMS discussion board, was related to ready access of notifications and the privacy of conversations. Ready access to notifications is somewhat related to the Evan's survey item on their empirical study: "Twitter is a good way to post things as soon as I think of them" (Evan, 2014, p.912), which positively inferred, together with other factors, strong use of social media for student engagement. The second finding related to the privacy of conversations is quite understandable among first year students who may be shy or embarrassed to share with unknown people in the class.

Anecdotal evidence suggests the increasing use of social media applications in supporting peer exchanges and cooperative endeavors. The unit investigated is about information systems and the message to students is around 'practising what you preach' and utilising ICT as the basis of communication via discussions, email, the Microsoft Lync synchronous discussion tool etc. The unit also has an active Twitter feed since its implementation and, interestingly, a Facebook page for the unit was implemented more recently as a means of providing an additional channel of communicating class news and information more generally and directly into a student Facebook feed if they choose to 'like' the page. However, the institutional online learning system remains the default means of communicating all teaching and learning materials, and communications to all student cohorts with both social media communication channels accessible from the LMS unit home page. Again, whatever the purported benefits of social media use for enhancing student engagement, more trialing and evaluation work is required to evidence learning gains as related to large mainstream blended learning developments.

Finally, there is one crucial element of blended learning practice that cannot necessarily be standardised and that is the behaviours of teaching staff who operate in their own local campus-based contexts and who might contribute in different ways to practice in the online environment. Student engagement and satisfaction may be dependent on the popularity and status of the teaching staff member on the respective campus, or servicing the needs of the Cloud student cohort, and the level of attention to their needs that they perceive. Having a Located, constant teaching staff member being the perceived leader on each campus, and for the Cloud cohort, can alleviate concerns around inconsistent service provision. So too can an inclusive leadership approach giving all key teaching staff an opportunity to create and contribute to the major learning resources made available to all student cohorts in a course. In whatever circumstance of this nature, it is important for the teaching team to maintain a strict focus on a prompt and consistent use and response to student questions online. Maintaining a consistent message is critical, which requires a small number of designated teaching staff members to be involved only in such activities. Otherwise, contradictory messages can abound that only serves to confuse students.

\section{Future developments}

The research continues to investigate the effects of design interventions on student engagement on particular subjects offered at different points of time over the two-year project period. The research will also report on more generalised blended learning design and practice activities which contribute to higher student engagement irrespective of the discipline, year of offer, and subject-based designs and practices in the business education domains. A specific point of interest will relate to a further and deeper investigation of any 
identified differences in patterns of student engagement based on key demographic and background factors of cohorts surveyed.

\section{Conclusion}

Multi-modal, multi-campus, diverse audience blended learning designs and practices is a hallmark of Australian higher education in the realm of business education. These types of blended learning environments raise pressing challenges in providing all students, irrespective of location, mode of delivery, background and motivation, will the best possible opportunity of mastering unit and course-wide learning outcomes. Assuring the mastery of desired learning outcomes is now central to university strategic curriculum design and course enhancement efforts. It is also a growing imperative in meeting external regulatory and professional accreditation requirements. Designing for student engagement provides a theoretically and conceptually grounded approach to enhancing and assuring student learning. The study has trialled the use of an online student engagement survey, with a dual focus on Cloud and Located learning experiences, and the relationship between the two. The findings have highlighted the importance of LMS interface designs to maximise the use and value of learning resources, the ways current LMS communication features are used by students, the perceived value of assessment functions operating effectively in online systems, and the emergence of alternative forms of communication and collaboration, which must be considered through the prism of social media. The balancing act still remains the development of online environments that cater for the needs of students who rely almost entirely on them to achieve the required learning outcomes, and those who best benefit from dual engagement with both Cloud and Located learning opportunities for learning achievement.

\section{References}

ACER (2014): http://www.acer.edu.au/ausse

Biggs, J. \& Tang, C. (2011). Teaching for Quality Learning at University. What the Student Does. Buckingham, England: Society for Research into Higher Education \& Open University Press.

Bonk, C.J. \& Graham, C.R. (2006). (Eds.). Handbook of blended learning: global perspectives, local designs. San Francisco, CA: Pfeiffer.

Bonk, C.J. \& Zhang, K. (2008). Empowering Online Learning: 100 + Activities For Reading, Reflecting, Displaying, \& Doing. San Francisco: John Wiley \& Sons.

Boud, D. (2010). Student Assessment for Learning In and After Courses. Final Report for Senior Fellowship. Australian Learning and Teaching Council (ALTC): http://www.olt.gov.au/resource-student-assessment-learning-and-after-courses-uts2010

Boud, D. \& Molloy, E. (2013). (Eds.). Feedback in Higher and Professional Education Understanding it and doing it well. London: Routledge.

Coates, H. (2006). Student engagement in campus-based and online education: university connections. Routledge: London.

Coates, H. (2010). Development of the Australasian survey of student engagement (AUSSE). Higher Education, 60:1-17.

Cull, W. L., O’Connor, K. G., Sharp, S. \& Tang, Suk-fong S. (2005). Response rates and response bias for 50 surveys of pediatricians. Health Services Research, 40(1):213-226.

Daniel, J.S. (1996). Mega-universities and Knowledge Media: Technology Strategies for Higher Education. London: Kogan Page.

Dey, E. L. (1997). Working with low survey response rates: The efficacy of weighting adjustments. Research in Higher Education, 38(2), 215-227. 
Evans, M. (2014). Twitter for teaching: Can social media be used to enhance the process of learning? British Journal of Educational Technology, 45(5):902-915.

Garrison, D.R. \& Anderson, T. (2003). E-Learning in the 21st Century. A Framework for Research and Practice. London: Routledge Falmer.

Garrison, D.R. \& Vaughan, N.D. (2008). Blended learning in higher education: framework, principles and guidelines. San Francisco: Jossey-Bass.

George-Walker, L. De., Hafeez-Baig, A., Gururajan, R. \& Danaher, P.A. (2010). Experiences and Perceptions of Learner Engagement in Blended Learning Environments: The Case of an Australian University in Y. Inoue (Ed.). Cases on online and blended learning technologies in higher education: concepts and practices. Information Science Reference, 23-43.

Graham, C.R. \& Robison, R. (2007). Realizing the Transformational Potential of Blended Learning: Comparing Cases of Transforming Blends and Enhancing Blends in Higher Education. In A.G. Picciano \& C.D. Dziuban (Eds.) Blended Learning: research perspectives. The Sloan Consortium, 84-110.

Graham, M. (2014). Social Media as a Tool for Increased Student Participation and Engagement Outside the Classroom in Higher Education. Journal of Perspectives in Applied Academic Practice, 2(3):16-24.

Holt, D., Segrave, S. \& Cybulski, J. (2011). (Eds.) Professional Education Using ESimulations: Benefits of Blended Learning Design. Hershey, US: IGI Global.

Johnson, T. P., O'Rourke, D., Burris, J., \& Owens, L. (2002). Culture and survey nonresponse. In R. M. Groves, D. A. Dillman, J. L. Eltinge \& R. J. A. Little (Eds.), Survey nonresponse. New York: Wiley, 55-69. ISBN: 978-0-471-39627-7

Kaleta, R., Skibba, K. \& Joosten, T. (2007). Discovering, Designing, and Delivering Hybrid Courses. In A.G. Picciano \& C.D. Dziuban (Eds.) Blended Learning: research perspectives. The Sloan Consortium, 112-43.

Kelm, O. R. (2011). Social Media: It's what students do. Business Communication Quarterly, 74(4):505-520

Krause, K-L \& Coates, H. (2008). Students' engagement in first-year university, Assessment \& Evaluation in Higher Education, 33(5):493-505.

Kristin, K. (2013). Teaching on the Education Frontier Instructional Strategies for Online and Blended Classrooms. Jossey-Bass: San Francisco.

Kuh, G.D. (2003). What we're learning about student engagement from NSSE. Change, 35(2):24-31.

Kuh, G.D., Kinzie, J., Schuh, J.H., Whitt, E.J., \& Associates (2005). Student success in college: Creating conditions that matter. San Francisco: Jossey-Bass.

Latcham, C. \& Jung, I. (2010). Distance and Blended Learning in Asia. Open \& flexible learning series. London: Routledge.

Nicol (2010). Re-engineering Assessment Practices in Higher Education: http://www.reap.ac.uk/Home.aspx

Lawson, R. (2015). Curriculum design for assuring learning - leading the way. Final Report for Senior Fellowship. Office for Learning and Teaching (OLT): http://www.olt.gov.au/resource-curriculum-design-assuring-learning-leading-way2015

Oliver, B. (2013). Graduate attributes as a focus for institution-wide curriculum renewal: innovations and challenges. Higher Education Research \& Development, 32(3):45063. 
Salmon, G. (2011). E-moderating. The Key to Teaching and Learning Online. $3^{\text {rd }}$ edition. New York: Routledge.

Sax, L.J., Gilmartin, S.K. \& Bryant, A.N. (August 2003) Assessing Response Rates and Nonresponse Bias in Web and Paper Surveys. Research in Higher Education, 44(4):409-432.

Scott, G. (2006). Accessing the Student Voice - Using CEQuery to identify what retains students and promotes engagement in productive learning in Australian higher education. Barton, Australian Capital Territory: Department of Education, Science and Training.

Shea, P. (2007). Towards A Conceptual Framework for Learning in Blended Environments. In A.G. Picciano \& C.D. Dziuban (Eds.) Blended Learning: research perspectives. The Sloan Consortium, 19-35.

Special Issue, Distance Education (2014). MOOCs: Emerging Research, 35(2), August. Rogelberg, S. G. \& Luong, A. (1998). Nonresponse to Mailed Surveys: A Review and Guide. Current Directions in Psychological Science, 7(2):60-65, April.

University Experience Survey (UES): https://www.education.gov.au/university-experiencesurvey

Copyright: (C) 2015 Pye, Holt, Salzman, Bellucci \& Lombardi. This is an open-access article distributed under the terms of the Creative Commons Attribution-NonCommercial 3.0 Australia License, which permits non-commercial use, distribution, and reproduction in any medium, provided the original author and AJIS are credited.

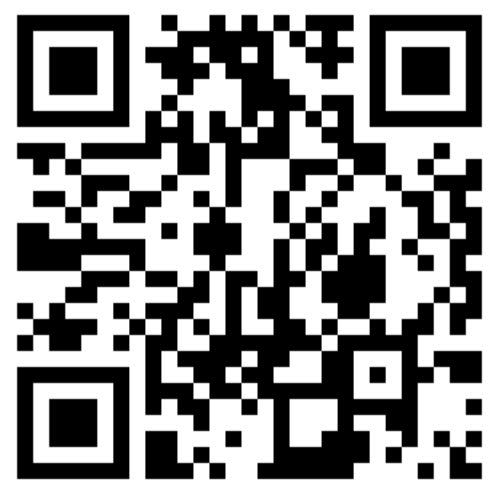

